\title{
Minireview Transport of proteins into the various subcompartments of mitochondria
}

\author{
Bartolome Segui-Real, Rosemary A. Stuart and Walter Neupert \\ Institut fï Phisiologische Chemie, Universitit Mänchen. W-8000 Minchen 2, Germany
}

Received 21 Seplember 1992

\begin{abstract}
The import of proteins into mitochondria is an intricale process comprised ol multiple steps. The first step involves the sorting of cytosolically synthesized precursor proteins to the milochondrial surface. There precursor proteins are recognized by specific rectuptors which deliver them to the genelal import sile present in the outer membrame. The second stage of import involves a series of complex intraorganelle sorting events which resulls in the detivery of the protcins to one of the lour possible submitochondrial destinations, namely the outer and inner menbranes, the matrix anc: alernembrane space. Here in this review, we diseuss the current knowledge on these intramitochondrial sorting events. We sspecially fosus on tal'geting of proteins to the intermembrane space. Sorting to the intemenbrane space represents a particularly inleresting situation, as at least inree separate targeting pathways to this subcompartment are known to exist.
\end{abstract}

Milochondria: Receptor: Prolcin sorting: Protsin translocation

\section{INTRODUCTION}

Mitochondria, like chloroplasts are believed to have originated from prokaryotic endosymbiotic ancestors. As a result of this evolutionary process these organelles have lost their autonomy. The vast majority of mitochondrial proteins are encoded by the cell nucleus and are synthesized in the cytoplasm, being imported into mitochondria as prectursor proteins in a post-translational manner. For this "new" targeting route, the eukaryotic cell has developed a number of devices to ensure the specific transport of these proteins to their correct functional locations.

Over the past couple of years progress has been made in the area of mitochondrial biogenesis which has given us new insights into these problems. In this review we will focus on the pathways of intramitochondrial sorting of precursor proteins. These control systems involve features of both the precursor protein themselves and components of their destination organelles. The accuracy and specifieity of the mechanisms involved allow the delivery of precursor proteins initially to the mitochondrial surface, from which they are sorted and assembled into the various mitochondrial subcompartments, namely outer membrane (OM), inner membrane (IM), matrix (M) and intermembrane space (IMS).

We shal! first diseuss the general import pathway that

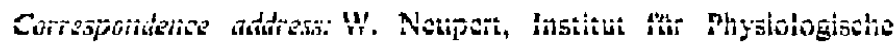
Chemie, Universital München, W-8000 München 2. Getmarty. Fax: (49) (89) 5996270. leads proteins into the matrix. We will then consider sorting to other subcompartments which in many cases appears to be a result of variations of the general pathway.

\section{MITOCHONDRIAL RECEPTORS}

The first stage in the mitoshondrial import of cytosolic proteins begins with the interaction of these proteins with $O M$ receptors $[4,31]$. Although at a functional level this step is not yet fully characterized, it seems that the targeting sequences of the precursor proteins (internal or cleavable amino-terminal presequences) are sufficient to directly interact with a receptor, A $19 \mathrm{kDa} O M$ receptor (MOM!9) has been shown to be responsible for recognition of the majority of precursor proteins [38.39]. Another OM receptor of $72 \mathrm{kDa}$ (MOM72/ MAS70; [13]) is specifically involved in the import of the ADP/ATP carrier [40] and perhaps of some other precursors [13]. In the absence of MOM72, its function is fulfilled by MOM 19, the two receptor's apparently have overlapping specificity [42]. A third OM protein of 22 kDa (MOM22) can be co-immunoprecipitated with these two components, however its functional role remuins unknown so far [3I].

How does translocation across the outer membrane occur after the binding of precursors to these receptors? Functional studies have shown that in a step following receptor binding, precursor proteins are presented to the general insertion site or pore (GIP) [17,27!. The receptors are part of a dynamic complex which includes several other components which are believed to consti- 
tute the GIP insertion and translocation site [4I]. A major role lies with an integral membrane protein MOM38 [17]/1SP42 [3]. Furthermore, two membrane associated proteins (MOM7, MOM8), and a less characterized protein (MOM30) are found in this complex [41]. These components could create a channel across the OM, which has been already predicted from functional import studies $[28,29]$. Thus, at this GIP stage, most of the precursor proteins are transported across or inserted into the OM.

\section{TRANSLOCATION INTO THE MATRIX}

The translocation pathway of precursor proteins into the matrix is probably the best studied mitochondrial import pathway. Since two membranes are involved at the same time it is rather complex. Precursor proteins destined to the matrix carry targeting sequences which in most cases are cleavable, positively charged and located at the amino-terminus of the preculsor protein [11]. These cleavable presequences have been shown 10 be necessary and sufficient to target and translocate the proteins to mitochondria in a receptor-dependent manner. Moreover, is has been recently reported that the OM receptor MOM19 can facilitate the import of a precursor protein by interacting specifically with its presequence [3].

The passage of precursors into the matrix has been assumed to occur through channels across the two membranes that are closely apposed. Interaction of precur'sors with the receptor-GIP system would not only lead to translocation across the OM, but also to insertion into a pore or channel through the IM. This model is supported by a variety of observations. Translocation intermediates which span both membranes could be accumulated in such a fashion that the amino-terminus is facing the matrix space (and the presequence is cleaved by the matrix processing peptidase) whereas the carboxy-terminus is still exposed to the cytosol (and can be degraded by added proteases). The sites in which spanning translecation intermediates are present were defined as 'translocation contact sites". Their number appears to be limited to several hundreds to thousands per mitochondrion $[2,32]$. After accumulation of precursors in translocation contact sites of isolated mitochondria, immune electron microscopy showed their presence in the areas where $O M$ and IM are in close proximity, i.e. 'morphological contact sites' or zones of adhesion.

A key problem in the translocation of proteins to the matrix is the nature of the driving force. A membrane potential $(\Delta \Psi)$ is required for the presequence to translocate across the $1 \mathrm{M}$ for the amino-terminus of the mature protein to reach the matrix space [23]. In addition, in the absence of a $\Delta \Psi$, precursors of matrix proteins are not luanslocated across the ồ. Pिrobabiy these precursors initiate translocation with their aminoterminal target sequences and thereby become inserted into or even across the OM, but in the absence of $\Delta 4^{\prime}$ this does not yield a stable intermediate.

On the other hand, once the amino-leminal sequence has responded to $\Delta \Psi$, further translocation across the IM into the matrix does not require $\Delta \Psi$. Subsequent completion of translocation of precursors across the IM requires a second driving force, namely that of Hsp70 action. In a temperature sensicive yeast mutant aflecting the gene encoding mitochondrial Hsp70, it was demonstrated that complete translocation into the matrix of these mitochondria was defective [16]. On the basis of these and other results, the following model concerning the bionergetics of translocation across the inner membrane into the matrix was proposed $[24,26,36]$. Initial targeting and triggering of matrix import is caused by the interaction of the matrix-targeting sequence with the inner membrane, in a $\Delta \psi^{*}$-dependent manner. Mitochond rial $\mathrm{Hsp} 70$ binds to the extended amino-lerminus of the precursor as it emerges on the matrix side of the translocation apparatus. By the interactican of one or more Hsp70 molecules, the precursor would be pulled towards the matrix, this process is thought to take advanlage of spontaneous unfolding of limited segments of the polypeptide chain on the outside of the mitochondria. Release of Hsp70 then requires ATP hydrolysis.

What do we know about the conformation of a polypeptide chain as it passes through both $\mathrm{OM}$ and $1 \mathrm{M}$ ? Experiments with chimeric proteins suggest a minimal length ( 50 amino acid residues) of the segment of the precursor that spans the two membranes at translocation contact sites [33]. This indicates that the polypeptide has a rather extended conformation as it passes through the membranes [34].

Recent observations have pointed a dynamic model of the organization of the transport machineries in $\mathrm{OM}$ and IM [32]. An enzyme of the IMS. cytochrome $\mathrm{c}$ heme lyase (CCHL, see below), was found to selectively use the machinery of the OM. This implies that some precursors are able to leave the "import pore" at the level of the IMS [21]. Secondly, intermediates were found where the amino-lerminus has reached the matrix and whilst the carboxy terminus had been translocated as far as the IMS [15.35]. Furthermore, mitoplasts were described to be able to import certain precursors [14]. Finally. fusion proteins consisting of CCHL and a matrix targeting signal could be imported in a two-step process, first into the IMS in the absence of $\Delta \Psi$, using the targeting information contained in $\mathrm{CCHL}$ and then into the matrix with $\Delta \Psi$, using the matrix targeting signal (Segui B. el al., unpublished results). Tha dynamic model resulting from this information is depicted in Fig. 1. It shows that the two machineries in OM and IM usually cooperate in a kind of continous 'channel" when translocating precursors. They may, however, only be formed after interation of a precursor with the recentor/GIP machinery of the OM. Intermembrane space components may be involved in forming this complex 


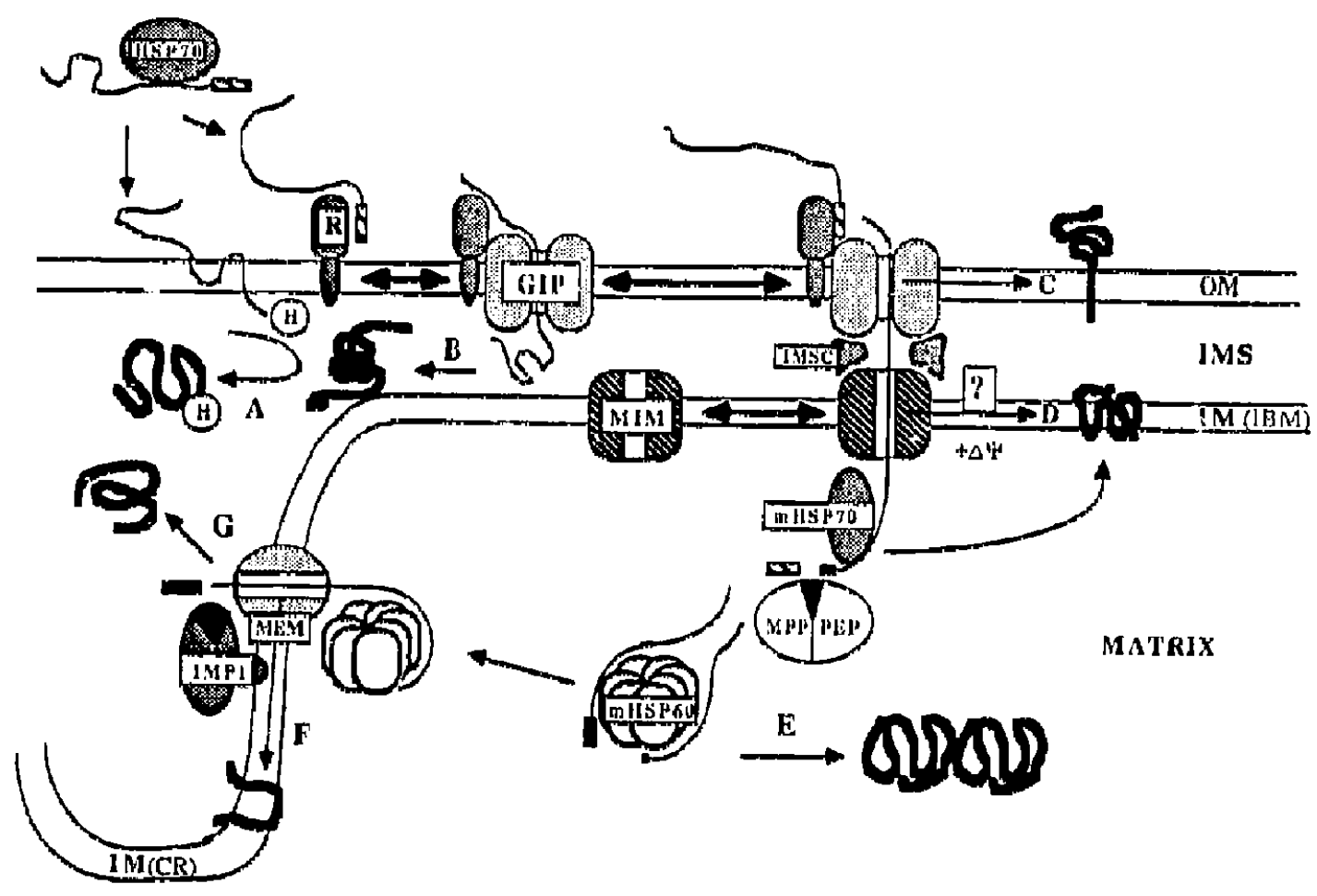

Fig. I. The difietent intlamitochondrial pathway taken by the various cylosolically syluthesized precursor proteins as doscribed in the text are shown lere. A-G depict the sorting steps lending to the final location of cyrochlome c, cylochrome cheme lyase (CClIL), MOM72, ADP/ATP cerrier $(A A C)$, subunit $\beta$ of the $F_{1}$ ATPust $\left(F_{1} \beta\right)$. Rieske Fe/S protein of the ubiguinol eytochrome $c$ red uctase complex and cytochrome $b_{2}$ respectively. Abbreviations used are as tollows: R, receptor; GlP, general insertion port; OM, ouler memblane; IMS intermembrane space; IMSC, intermentbrune space component; IM, inner membrane; IBM, inner boundary membranu; CR, erisiac: mHsp70, milochond rital HSP70; MPP, mitochondrial processing peptidase; PEP, prolesse anhancing protein; MEM, mitoclıondrial import machinery: MIM, mitochondrial inport machinery (inner mambrane); IMPI, inner menbrane protease $I$.

entity. Whether productive 'OM/IM channels' can be formed only at morphological contact sites (where the two membranes are in close physical contact) or also outside these sites (randomly where $O M$ and inner boundary membrane are closely apposed) remains to be seen. It is also an open question whether ' $\mathrm{OM} / \mathrm{IM}$ channels' are sealed in such a way that there is no access to the translocating chain from the IMS, or whether parts of the polypeptide chain in transit are exposed to the IMS.

Following transport of precursors into the matrix, precursors undergo sleavage of their targeting sequences, a reaction catalyzed by the matrix localized processing enzyme, which consists of two components (matrix processing peptidase; MPP or MAS2/MIF2 protein and processing enhancing protein; PEP or MAS1/MIF2 protein) [1]. Subsequent folding (and perhaps oligomerization) of the matrix proteins is then facilitated by Hspon [25].

\section{TRANSLOCATION INTO THE INTERMEM- BRANE SPACE}

\subsection{Sorting of cyiochromes $\mathrm{b}_{2}$ and $\mathrm{c}_{i}$}

The precursors of eytochromes $b_{2}$ and $c_{1}$ have two amino-terminal signals arranged in tandem which direct the proteins into the IMS in two steps. The first sequence is a typical matrix targeting signal that directs the precursor into the matrix along the pathway described above, where it is cleaved by the matrix processing peptidase. The second part of the presequence then acts as an "sorting' signal that directs the protein into the IMS [9].

The evidence of such a pathway is as follows: under appropriate conditions, intermediate sized forms (i.e. where the first signal is removed) can be found in the matrix space. There, it is seen in transitory association with Hsp60 $[6,18]$. The other chaperone of the mitochondria, Hsp70, is also involved, as mutants in Hsp70 show a defect in the sorting of e.g. cytochrome $b_{2}[16]$. Hsp60 is necessary since in conditional Hsp60 mutants, sorting to the IMS is impaired [0]. The second sorting signal resembles bacterial export signals and eukaryotic secretion signals in two respects: it contains a hydrophobic core and one or more positively charged residues at the amino-terminal side of that sequence [10].

It has been recently argued that eytochromes $b_{2}$ and $i_{1}$ do not reach the matrix, but that their transfer is stoppad when the second signal enters the IM [7]. The evidence brought forward in favour of such a pathway was that intermediates were not found in the matrix, that ATP was not required for the import and that 
import was not affected in a Hsp60 mutant. It can presently not be excluded, simply on iogieal grounds, that such a pathway would exist, however, experiments are required that will provide positive evidence for a "stoptransler' pathway.

The complex sorting pathway of cytochrome $b_{2}$ and $c_{1}$ can be rationalized by considering its possible evolution. Various mitochondrial components of the respiratory chain are apparently derived from prokaryotic components which have equivalent function in bacteria and which are closely similar in terms of amino acid sequence. For instance, cytochrome $c_{1}$ of Rhodobacter spheroides can be directly compared to mitochondria! cytochrome $c_{1}$. Yet, in Rhodobacter, cytochrome $c_{1}$ is synthesized in the bacterial cytosol and exported towalds the periplasmic space [12]. The conservative sorting hypothesis suggests that this sorting pathway has been conserved (as has been the sorting signal) and that in order to embark on the ancestral sorting pathway the precursor has first to be imported into the matrix along the general import pathrray [10]. According to this hypothesis it seems possible that the export of these precursor's with a bipartite sequence oecurs via those sites that are engaged in the mumbrane insertion of proteins encoded by mitochondrial genome and synthesized by mitochondriai ribosomes.

So far, our knowledge about the latter process is extremely poor. There, is however, one indication for such a common pathway. The protease IMPI [37] that cleaves the precursor of cytochrome oxidase subunit II (a mitochond, ial gene product) in the IMS also processes the second import signal of cytochrome $b_{2}$.

The "conservative sorting hypothesis", in fact, provides the simplest explanation for the complex sorting of cytochrome $b_{2}$ and $c_{1} . A$ stop transfer mechanism is seemingly simple as the movement of the precursor appears relatively simple. A conservative pathway is, in fact, much easier to rationalize if one considers that the role of the transport machineries as being a more eritical point of view. Conservative sorting does nol require additional, 'new' components, since the import and export machineries which exist, can be used. Sorting according to "stop transfer" would have to postulate an additional new complex apparatus that precisely recognizes the various features of sorting signals, such as a hydrophobic core and positive charges at the aminoterminus.

Clearly, one must not discuss conservation of sorting in a dogmatic manner since a few proteins are known (see below) which are not targeted to the IMS in a conserved manner. In those cases, however, the signals that strongly resemble the prokaryotic ones are absent. Future experiments will have to identify the components of the mitochondrial 'export' apparatus. We will then be able to tell whether the prokaryotic system his been conserved and whether it not only handies mito- chondrial gene prociucts but also those nuclear encoded proteins that are sorted via the matrix to the IMS. Finally, sorting via the matrix has also been shown for two proteins of the mitocliondrial IM, the R ier!n Fe/S protein [8] and subunit 9 of FoATPase [22]. Quite interestingly, like in their bacterial equivalents, the second sorting signal is present here in the mature part of this protein.

\subsection{Selective sorting across the outer membrathe: cyto- chrome cheme lyase (CCHL)}

The import pathway used by CCHL is different from the pathway used by those. IMS proteins discussed above. It shares, however, certain characteristics with the general import path way into the matrix. The CCHL precursor lacks a cleavable (single or bipartite) presequence, it is translocnted selectively across the $O M$ and does not require an energized IM [21]. However, like cytochrome $b_{2}$ and $c_{1}$, it interacts with the MOM19 receptor on the surtace of the mitochondria, and then appear's to use GIP $[20,21]$.

Two interesting questions arise from this particular import pathway. The first one regards the driving force that 'pulls' CCHL across the OM into the IMS. An ATP requirement for CCHL import has not been found. It seems possible that this protein is in a loosely folded conformation alter its synthesis. Folding in the IMS or interaction with a membranous component in the IMS could then drive its translocation across the OM.

The second question relates to the final location of CCHL in the IMS. Why does CCHL not enter the IM or the matrix? The answer to this question is most likely that $\mathrm{CCHL}$ does not have a matrix-targeting sequence. In fact, when a matrix targeting sequence is fused to the amino-terminus of CCHL, this hybrid protein can be first translocated into the IMS, and then into the matrix, or directly along the general import pathway to the matrix (B. Segui, et al.n unpublished results).

\subsection{Unizus pathway' of cyloultrome c}

Cytochrome $c$, a soluble protein of the IMS, is imported by an exceptional pathway. Cytochrome c, synthesized as a precursor known as apocytochrome $c$ does not contain a cleavable presequence and diflers from its mature counterpart in that it lacks its covalently attached heme group. Apocytochrome $c$ does not require the receptor/GIP machinery for insertion into the OM. Due to its very membrane active nature it is believed to spontaneously insert into the OM independently of other proteinaceous components [43]. Subsequent impor: of this intermediate is then driven by a specific interaction with eytochrome $c$ heme lyase (CCHL), the enzyme responsible for catalyzing the covalent heme attachment to cytoclirome c. Thus, CCHL may function like a receptor and a chaperone at the same time [44]. 


\section{TRANSLOCATION INTO THE INNER MEM- BRANE}

The topogenesis of nuclear-encoded proteins of the IM has not been investigated in great detail. This is due to the fact that the exact topology has been established only for a few IM proteins. Furthermore. there are considerable experimental problems in determining whether a typical IM protein has reached its correct location and folding state. Nevertheless, a number of insights have been gained.

There is a class of IM proteins that use the genelal sorting pathway into the matrix and then become inserted into the IM from the matrix side. Examples described are the Rieske $\mathrm{Fe} / \mathrm{S}$ protein of the ubiquinal cytochrome $c$ reductase complex [8] and subunit 9 ('proteolipid') of the $F_{0}$ part of mitochondrial ATP synthase [22]. The evidence for the passage of these proteins through the matrix is as follows: intermediates can be found in the matrix under certain conditions and both Hsp70 and Hsp60 in the matrix were observed to be required for sorting [18]. This complex way of entering the IM can be explained on the basis of "conservative sorting", since in prokaryotes. proteins homologous in structure and function are inserted from the cytosolic side of the eqaivalent plasma membrane. The prokaryotic precursor forms of the $\mathrm{Fe} / \mathrm{S}$ protein and subunit 9 lack presequences, as do the forms of the mitochondrial precursors that are processed by MPP/PEP. The information for the insertion of the mitochondrial precursol's into the IM apparently resides in the mature parts, as is the case with the bacterial versions [10].

Are there other pathways for inserting proteins into the IM? We do not know whether insertion, for instance, can occur from the IMS side into the IM or whether, in analogy to the endoplasmic reticulum, insertion can occur by stop transter, i.e. when a polypeptide chain is being translocated through the IM machinery. The import of mitochondrial ADP/ATP carrier was observed to require Hsp70 but not Hsp60 [26]. The ADP/ ATP carrier does not have a cleavable signal at the amino-terminus, but rather has multiple targeting information in the interior of the mature part $[30,45]$. It remains to be shown whether this particular type of IM proteins (which includes a whole fannily of related proteins) has developed specific strategites for insertion into the $1 \mathrm{M}$.

\section{TRANSLOCATION INTO THE OUTER MEM- BRANE}

Translocation into the OM appears to entail the most simple targeting pathway into mitochondria, as only direct insertion into a membrane is involved. Still, this renction is not very well understood. We know that most OM components need the receptor machinery, e.g. porin, MOM72 or MOM38, but this clearly does not hold for all OM proteins. MOMlg was found to be inserted without its own help or that from MOM72, but required MOM38/GIP for stable integration [38]. The signals which are responsible for the specificity of inser. tion and that determine the orientation in the OM are largely unknown. It seems possible that they are contained in or near the hydrophobic segments [19], but detailed information is lacking. Furthermore, an intriguing question is how the multiple beta strands of mitochondrial porin are inserted into the OM.

\section{PERSPECTIVES}

It is apparent from what has been discussed here that our knowledge of how precursor proteirs reach their functional compartments can best be called fragmentary.

The analysis of the precise function of targeting sequences, the analysis of import pathways and the identification of new components of the translocation machineries and of their active domains has to be continued. The mechanisms of sorting of mitochondrially encoded proteins need to be addressed.

Studies using partial systems and reactions to look at individual sorting steps, will deepen our insights into the molecular basis of targeting proteins to the various subcompartments of an organelle as complex as the mitochondrion.

\section{REFERENCES}

[1] Arrel\%, M., Sshneider, H. Wienhues, U. and Neupcri, W. (1991) Bioned. Biochim. Acta 50, 403-412.

[2] Altardi, G. and Schatz, G. (1988) Annu. Rev. Cell. Biol. 4, 289333.

[3] Baker, K.P., Schuniel, A., Vesiweber, D. and Schutz, G. (1990) Nature 348, 605-609.

[4] Baker, K.P. and Schatz, G. (1991) Nature 349, 205-203.

[5] Becker, K., Guiard, B., Ralssow, J., Sölnnur, T. and Pranner, N. (1992) J. Biol. Chem. 267, 5637-5643.

[6] Cheng, M.Y., Haru, F.U., Malrin, J, Pollock, R.A., Kalousek, F., Neuperl, W.. Hallberg, E.M.. Hallbere, R.L. and Horwich, A.L. (1989) Nature 337, 620-025.

[7] Glick, B. Brandı, A., Cunningham, K., Muller, S., Hallberg, R.L. and Schatz, G. (1992) Cell 69, 809-822.

[8] Haltl, F.U., Schmidt, B., Wachter, E., Weiss, H. and Neupeli, W. (1986) Cell 47, 939-951.

[9] Hart, F.U., Otimmann, J., Guiard, B. and Neupert, W. (1968; Cell 51. 1027-1037.

[10] Hart, F.L. and Neupert, W. (1990) Science 247, 930-938.

[11] Hartl, F.U., Pfanner N., Nicholson, D.W. and Neupert, W. (1989) Blochim. Biophys. Acta 988, 1-45.

[12] Hauska, G., Nitschke, W. and Herrmann, R.G. (I988) J. Bioenerg. Biomembr. 20, 211.

[13] Hines, V., Brand, A., Griffilhs, G., Horsinennn, H., Brutsch, H. and Selatz, O. (1990) EMBO J. 9. 3191-3200.

[14] Hwang, S., Jascur, T., Vsutweber, D., Pon, L. and Schatz, G. (1989) J. Cell. Biol. 109. 487-493.

[15] Hwang, S.T.. Wuchter. C. and Schatz, G. (1901) J. Biol. Chem. 260. 21083-21089.

[16] Kang, P.J., Ostermam, J., Shilling, J., Noupert, W., Craig, E.A. and Pfanner, N. (1990) Nature 348, 137-143.

[17] Kiebier, M., Pfaller, R., Söllner, T.. Griffiths, G., Horstmann, H., Pranner, N. and Neupert, W. (1990) Nature 348, 610-610. 
[18] Koll, H., Guiard, B., Kassow, J., Ostermann, J., Horwich, A.L., Neupert, W. and Hartl, F.U. (1992) Cell 68, 1163-1175.

[19] Li, J,M. and Shore, G.C. (1992) Science 256, 1815-1816.

[20] Lill, R., Hergersberg, C., Schneider, H., Súllnar, T., Stuarı, R. and Neupert, W. (1992) Membrane Bicgenesis and Protsin Targeting. (W. Maupert and R. Lill, Eds.) in press.

[21] Lill, R., Stuar:, R.A., Drygas, M.E., Nurgang. F.E. and Neupert, W. (1992) EMBO J. 11, 449-456.

[22] Mahlke, K., Pfanner. N., Martin, J., Horwich, A.L., Hartl, F.U. and Neupert, W. (1990) Eur. J. Biochem. 192, 551-555.

[23] Martin. J., Mahlke, K. and Planner, N. (1991) J. Biol. Chem. 266, 1805!-18057.

[24] Neupert, W., Hart, F.U., Craig, E.A. and Pfinner, N. (1990) Cell 63, $447-450$.

[25] Ostermann, J., Horwich, A.l., Neupert, W. and Hartl, F.U. (1989) Nature 341, 125-130.

[20] Ostermann, J., Voos, W., Kang, P.J., Craig, E.A., Neupert, W. and Franmel, N. (1990) FEBS Latt. 277, 281-284.

[27] Plaller, R., Steger, H.F., Rabsow, J. Planner, N. and Neupert, W. (1988) J. Cell. Biol. 107, 2483-2490.

[28] Planner, N., Harll, F.U., Guiard, B. and Neuperi, W. (1987) Eur. J. Biochem. 169. 289-293.

[29] Planner, N., Mullar, H.K., Harmey, M.A. and Neupert, W. (1987) EMBO J. 6, 3.449-34.54.

[30] Planner, N., Hoeben, P., Tropsehng, M. and Neupel', W. (1987) J. Biol. Chem. 262, 14851-14854.

[31] Pfanner, N., Sollner, T. and Neupert, W. (1991) Trends Biochern. Sci. 16, 63-67.
[32] Planuer, Ni., Rassow, I., yan der Klei, I. and Neujkelt, W. (1992) Cell 68, 909-1002.

[33] Rassow, J., Guiard, B., Wienhuss, U., Herzog, V., Hart, F.U. and Neupert. W. (1989) J. Cell. Biol. 109, 1421-1428.

[34] Rassow, J.. Hartl, F.U., Guiard, B., Pfanner, N. and Neuper, W. (1990) FEBS Litt. 275, 190-194.

[35] Russow, J. and Pfanner, N. (1902) FEBS L.4tt. 293, 85-88.

[30] Scherer, P.E., Krieg, L.C., Hwang, S.T., Ycstwsber, D. and Schitz, G. (1990) EMBO J. 9, 4315-4322.

[37] Scluneider, A., Behrens. M., Scherer, P.. Pralje. E.. Michaelis, G. and Schatz, G. (1991) EMBO J. 10, 247-254.

[38] Schneider, H., Süliner, T., Diemeier, K., Eekerskorn, C., Louspeich, F., Trülzsch, B., Neuperl, W. and Panner, N. (1991) Science 254, 1659-1662.

[39] Söllner, T., Griffiths, G.. Plaller, R., Pfanner, N. and Neupert. W. (1989) Call $59,1001-1070$.

[40] Söllner, T., Pfaller, R., Griffiths, G., Pfunner, N. and Neuper, W. (1990) Cell 62, 107-115.

[4I] Söllner, T., Rassow, J., Wírdmann, M., Schlossmann, J., Keill, P., Neupert. W. and Planner, N. (1992) Nalure 355. 84-87.

[42] Slèger, H.F., Söliner, T., Kiebler, M.. Distmeyer, K., Plaller. R., Trülzsch, K.S., Tropsehung, M., Neuperl, W. and Pofurner, N. (1990) J. Cell. Biol. 111, 2353-2363.

[43] Sibart, R.A., Nicholson, D.W. and Neupert, W. (1990) Cell 60. $31-49$.

[A4] Stuatt, R.A., and Neupert. W. (1900) Biochemis 72, 11 5-121.

[45] Smagula, C.S. and Douglas, M.G. (1988) J. Cell. Biochem, 36. 323-327. 